\title{
Oxidation of Sputtered Deposited Carbon Studied by Electrochemical Quartz Crystal Microbalance
}

\author{
Amar Prasad Yadav ${ }^{*}$ \\ Central Department of Chemistry, Tribhuvan University, Kirtipur, Kathmandu, Nepal \\ Email:amar2y@yahoo.com
}

\begin{abstract}
The oxidation behavior of a sputtered carbon electrode has been investigated in $0.5 \mathrm{M} \mathrm{H}_{2} \mathrm{SO}_{4}$ solution with the help of an electrochemical quartz crystal microbalance (EQCM). The mass change response of the carbon coated Au-QCM during potential cycling showed an increase of mass due to adsorption of water or bisulfate ion just after observation of an anodic peak for the oxidation of hydroquinone. A mass loss due probably to the evolution of $\mathrm{CO}_{2}$ gas was observed at potential above 1.3 $V$ vs. SHE during anodic scan. During cathodic scan, a loss of mass due to release of water or bisulfate ion was accompanied by the reduction of quinone to hydroquinone.
\end{abstract}

Keywords: Sputtered carbon, EQCM, PEFC, Quinone-hydroquinone

\section{Introduction}

The polymer electrolyte fuel cell (PEFC) is being extensively researched as an alternate energy conversion and efficient power sources device due to its environmentally clean working condition. The commercialization of PEFC is not yet possible due to tough requirements regarding costs, power density, robustness and long term stability ${ }^{1}$. Among them, the stability of carbon as a noble metal catalyst support is not well known especially at cathode, where the open circuit voltage (OCV) is about $1.0 \mathrm{~V}$. Thermodynamically carbon can undergo oxidation at potential above $0.207 \mathrm{~V}$ vs. SHE$^{2}$. Oxidation of carbon can lead to loss of performance of PEFC due to loss of active surface area resulting from detachment of Pt particles, decrease of electronic continuity of the catalyst layer and alteration of pore morphology and pore surface characteristics.

In this study, an attempt has been made to use the electrochemical quartz crystal microbalance (EQCM) as a tool to identify the oxidation state of carbon in acidic medium.

\section{Experimental}

A Hokuto Denko EQCM system was used in this study, which consisted of an oscillating circuit (HQ-304C), a frequency counter (HQ-101D) and a potentiostat (HZ-5000) controlled by a personal computer through a GPIB interface. An AT-cut Au quartz crystal (QC) with a fundamental frequency of 6 $\mathrm{MHz}$ in air was used as a mass sensor. Each quartz crystal had a $1.33 \mathrm{~cm}^{2}$ circular area on each side. One side of the QC was coated with carbon by thermal evaporation of a graphite rod at the base pressure of 4 x $10^{-7}$ Torr. The carbon layer thickness was fixed at about $40 \mathrm{~nm}$. In order to know the oxidation behavior of carbon, cyclic voltammetry $(\mathrm{CV})$ of carbon deposited QC was carried out in $0.5 \mathrm{M} \mathrm{H}_{2} \mathrm{SO}_{4}$ solution in nitrogen atmosphere in the potential range of $0.0-1.5 \mathrm{~V}$ vs. SHE at a scan rate of $10 \mathrm{mV} / \mathrm{s}$. A

\section{* Corresponding author}


KCl-saturated silver/silver chloride electrode (SSE) with a double junction was used as a reference electrode and Au wire was used as the counter electrode. The potential values are referred to the SHE. All the measurements were made at $298 \mathrm{~K}$ with solutions prepared in triply distilled water.

During CV, the mass change response at QC was recorded and interpreted in terms of contribution from various processes on the carbon surface. From the EQCM system, mass change per unit area, $\Delta m$, is calculated from the changes in resonance frequency, $\Delta f$, using the Sauerbrey equation ${ }^{3}$ :

$$
\Delta m=-C_{f} \Delta f
$$

where $\mathrm{C}_{f}$ is the sensitivity factor of the QCM. For a $6 \mathrm{MHz}$ QCM operating in its fundamental mode, the theoretical sensitivity factor comes around $16.02 \mathrm{ng} \mathrm{Hz}^{-1}\left(12.05 \mathrm{ng} \mathrm{Hz}^{-1} \mathrm{~cm}^{-2}\right)$. The change of frequency was measured at a gate time of $1 \mathrm{~s}$, which gave a frequency resolution of $0.2 \mathrm{~Hz}$. The effect of CV and hold potential on the wettability of carbon surface was investigated by measuring the contact angle of a micro droplet of water.

\section{Results and Discussion}

\section{CV and EQCM response of carbon deposited QCM}

Figure 1 shows the $\mathrm{CV}$ and corresponding mass change response of as deposited carbon-QCM in 0.5 $\mathrm{M} \mathrm{H}_{2} \mathrm{SO}_{4}$ solution at $298 \mathrm{~K}$ in nitrogen atmosphere in the potential range $0.0-1.2 \mathrm{~V}$ at a scan rate of 10 $\mathrm{mV} / \mathrm{s}$. The $\mathrm{CV}$ shows a redox reaction occurring at about $0.70 \mathrm{~V}$. Irrespective of the potential, the EQCM response only showed a mass gain throughout the CV. This continuous mass gain shows that the as deposited carbon surface had very limited wettability. This means the electrochemically active area was very low for the as deposited sample. With the repeated potential scan, the sample started to show the mass change response in relation to cathodic and anodic scan after 15 cycles of CV. However, to accelerate the oxidation of carbon surface, it was held at $1.2 \mathrm{~V}$ for $12 \mathrm{~h}$ before using for CV. All the results reported in coming section will be after holding the carbon electrode at $1.2 \mathrm{~V}$ in $0.5 \mathrm{M} \mathrm{H}_{2} \mathrm{SO}_{4}$ solution.

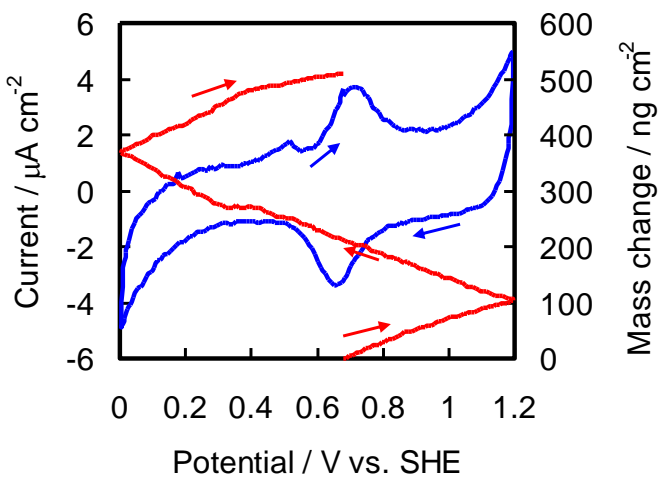

Fig.1 CV and mass change response of as deposited carbon-QCM in deaerated $0.5 \mathrm{M}$ $\mathrm{H}_{2} \mathrm{SO}_{4}$ solution at $298 \mathrm{~K}$, scan rate $10 \mathrm{mV} / \mathrm{s}$

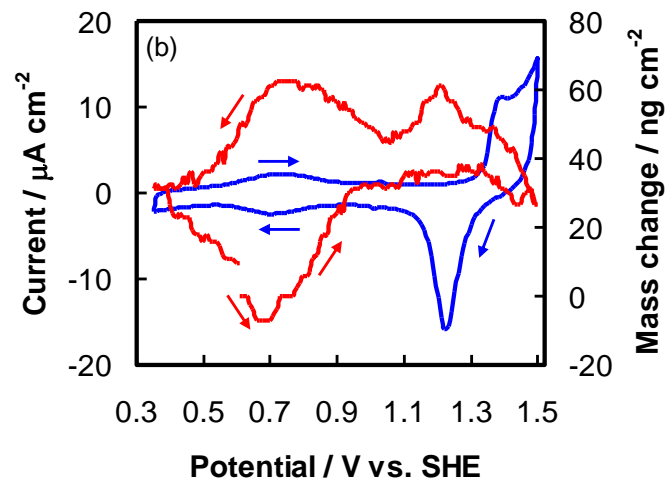

Figure $2 \mathrm{CV}$ and corresponding mass change response of a carbon deposited QCM at upper potential limit of $1.5 \mathrm{~V} v \mathrm{~s}$. SHE. 
Before going to discuss the origin of mass change at QCM, the reported mechanism of electrochemical corrosion of carbon is discussed. It is generally thought that the corrosion of carbon proceeds via a three-step process involving four electrons ${ }^{2}$. In the first step the carbon is oxidized in the lattice (Step 1) at above $0.207 \mathrm{~V}$. This allows the formation of oxidized carbon intermediates by two electron partial oxidation (Step 2). The intermediates may be electro-active such as the quinone/hydroquinone redox couple ${ }^{4}$ or other species such as carbonyls, alcohols, and carboxylic acids. The final step of corrosion process (Step 3) is the formation of carbon dioxide.

Step 1 Oxidation of the carbon in the lattice $\mathrm{C}_{\mathrm{s}} \rightarrow \mathrm{C}_{\mathrm{s}}^{+}+\mathrm{e}^{-}$

Step 2 Hydrolysis of oxidized lattice carbon $\mathrm{C}_{\mathrm{s}}^{+}+1 / 2 \mathrm{H}_{2} \mathrm{O} \rightarrow \mathrm{C}_{\mathrm{s}} \mathrm{O}+\mathrm{H}^{+}$

Step 3 Gasification to carbon dioxide: $2 \mathrm{C}_{\mathrm{s}} \mathrm{O}+\mathrm{H}_{2} \mathrm{O} \rightarrow \mathrm{C}_{\mathrm{s}} \mathrm{O}+\mathrm{CO}_{2}+2 \mathrm{H}^{+}+2 \mathrm{e}^{-}$

Net reaction: $\mathrm{C}+\mathrm{H}_{2} \mathrm{O} \rightarrow \mathrm{CO}_{2}+4 \mathrm{H}^{+}+4 \mathrm{e}^{-}, E=0.207 \mathrm{~V} \mathrm{SHE}$

From the above discussion, the redox peak in Fig.1 can be assigned to the oxidation-reduction of hydroquinone-quinone (HQ/Q) system ${ }^{2,4}$. The reodx potential of HQ/Q can be given as:

$$
\begin{array}{ll}
\mathrm{HQ}+\mathrm{OH}^{-} \Leftrightarrow \mathrm{Q}+\mathrm{H}_{2} \mathrm{O} & 2 \\
\mathrm{E}=\mathrm{E}_{0}-0.0591 \mathrm{pH} & 3
\end{array}
$$

It is common practice to use the evolution of the redox peak of HQ/Q to characterize the oxidation state of the carbon.

After confirming the formation of HQ/Q couple, the CV was carried out in the potential range of 0.35-1.5 V. Figure 2 shows the $\mathrm{CV}$ and corresponding mass change responses at upper potential limit of $1.5 \mathrm{~V}$. First, the $\mathrm{CV}$ and corresponding mass change till upper potential limit of $1.2 \mathrm{~V}$ is discussed. As mentioned before, the redox peak at about $0.7 \mathrm{~V}$ can be assigned to the HQ/Q. During anodic scan, the mass change increased exactly from the maximum of the oxidation peak due to oxidation of hydroquinone $(0.7 \mathrm{~V})$ until $1.0 \mathrm{~V}$, after which the slope of mass change slightly decreased. When the potential was reverse to cathodic direction, the mass change slightly increased before decreasing drastically from the cathodic peak due to reduction of quinone $(0.7 \mathrm{~V})$. Again, when the potential was reversed to anodic direction, the mass change decreased fairly till the beginning of oxidation of hydroquinone.

It can be expected from reaction in equation 2 that the oxidation of HQ should result in the loss of mass. On the contrary, an increase of mass was obtained. We think that the oxidation at $0.7 \mathrm{~V}$ make the carbon surface hydrophilic and therefore, adsorption of water leads to increase of mass. However, the increase of polarization potential increases the amount of surface oxides together with the increase in the amount of gaseous oxides. This can fill the pores of the carbon and limit the penetration of water. After the potential was reversed, the gaseous species formed in the previous scan should stabilized resulting in almost no change in mass until 1.0 V. The mass change increased from $1.0 \mathrm{~V}$ before the start of reduction of quinone $(0.7 \mathrm{~V})$ can be related to the rearrangement of water molecules. After the reduction of quinone commences $(0.7 \mathrm{~V})$, the mass change decreased due to loss of adsorbed water molecules. This shows that the carbon surface changed to hydrophobic with the formation of HQ. It is very interesting observation which means that if the OCV of operating PEFC is less than $0.7 \mathrm{~V}$ the oxidation of carbon can be very low due to hydrophobicity of the surface. However, it needs further study to clarify this observation.

The decrease of mass change continued even after the potential was reversed to anodic direction, which is again related to the hdrophobicity of the surface as otherwise an increase of mass could be obtained if reaction in step 2 is considered. This result shows that the complete oxidation is required for the adsorption of water on carbon surface and this can be used as an indicator of the surface state of carbon in PEFC. 


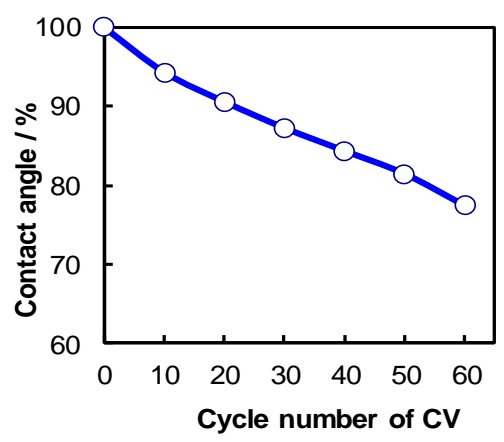

Figure 3: Effect of $C V$ and potential on the change of contact angle of a $6 \mu l$ water droplet on sputtered depsited carbon-QCM. The CV was run between 0.35-1.2 Vvs. SHE in deaerated 0.5 $\mathrm{M} \mathrm{H}_{2} \mathrm{SO}_{4}$ solution after holding the electrode at 1.2 for $12 \mathrm{~h}$.

The mass change response when the upper potential limit was at $1.5 \mathrm{~V}$, can be explained by considering the involvement of redox peaks for gold of QCM the when potential was more positive than $1.3 \mathrm{~V}$. The anodic peak at 1.30 and corresponding cathodic peak at $1.2 \mathrm{~V}$ were therefore assigned to gold substrate due to thin and porous nature of the carbon film. The anodic peak at $1.39 \mathrm{~V}$ was due to oxidation of water, which did not have any effect on the mass change response. It can be seen that the oxidation of gold resulted in the decrease of mass $(1.25-1.5 \mathrm{~V})$, which should otherwise increase due to formation of gold-oxide. We think that the oxidation of gold resulted in the loss of carbon and adsorbed water molecules. When the potential was reversed in the cathodic direction, the loss of carbon and water stopped and the mass change increased again until the reduction of gold-oxide. This mass increase was probably due to adsorption of water molecules. After reduction of the gold-oxide almost no mass change was obtained at about $1.0 \mathrm{~V}$, which shows that the mass change in between 1.0-1.5 V was related to the reaction occurring on the gold surface.

The effect of $\mathrm{CV}$ and hold potential on the wettability of carbon surface was investigated by measuring the contact angle of a micro droplet of water. Figure 3 shows the change in the contact angle of a $6 \mu \mathrm{l}$ water droplet on the carbon surface after running CV. The decease of contact angle can be interpreted as the increase in the surface oxidation of carbon.

\section{Conclusions}

This study shows that the carbon corrosion can be studied by using EQCM. The mass change response of carbon during $\mathrm{CV}$ gives information regarding the affinity for water and it can be very useful in deciding the corrosion condition for carbon in PEFC.

\section{Acknowledgements}

The author would like to thank Prof. Atsushi Nishikata, Tokyo Institute of Technology, Tokyo, Japan for making available all the facilities required for this work.

\section{References}

1. A. S. Feitelberg, J. Stathopoulos, Z. Qi, C. Smith, J. F. Elter, J. Power Sources, 2005, 147, 203.

2. K. Kinoshita, JAS Bett, Carbon, 1974, 12, 525.

3. G. Sauerbray, Z. Phys, 1959, 155, 206.

4. K. H. Kangasniemi, D. A. Condit, T. D. Jarvi, J.Electrochem.Soc., 2005, 151, E125. 